\title{
Severe Adult-Onset Calcinosis in a Patient with a History of Juvenile Dermatomyositis
}

PETROS EFTHIMIOU, MD, Director, Weill Cornell Medical College of Cornell University; MANIL KUKAR, MD, Research Associate, Rheumatology Division, Lincoln Medical and Mental Health Center, 234 East 149th Street, New York, NY 10451; LAWRENCE J. KAGEN, MD, Weill Cornell Medical College of Cornell University, Attending Physician, Hospital for Special Surgery, New York, NY, USA. Address correspondence to Dr. Efthimiou; E-mail: petrosefthimiou@gmail.com. J Rheumatol 2010;37:194; doi:10.3899/jrheum.090628

Calcific deposits develop in $20 \%-40 \%^{1}$ of children with juvenile dermatomyositis (JDM); however, calcinosis is a rare feature in adults with dermatomyositis ${ }^{2,3}$. In adults, calcification often presents as firm subcutaneous nodules that are frequently most prominent around sites of repeated microtrauma, such as elbows, knees, buttocks, and hands. Calcification of muscles is frequently asymptomatic and observed as an incidental finding in radiographs. Our case illustrates a rare finding of adult-onset severe calcinosis in JDM. These calcifications, apart from the aesthetic deformity, limit the range of movement of extremities and predispose to skin ulceration and superinfections.

A 46-year-old man presented with subcutaneous indurated masses. He had a history of severe JDM since the age of 6 years, with partial response to corticosteroid treatment. Examination revealed multiple large subcutaneous calcific deposits in both upper and lower extremities. Calcium deposits had first been noted at age 27 years on the flexor surfaces of the arms and thighs; at that time he denied concurrent muscle weakness. Over the years, these deposits enlarged and caused discomfort and limitation of range of movement (Figure 1). Plain radiographs of the upper and lower extremities revealed areas of soft-tissue calcifications. Bone imaging with $99 \mathrm{M}_{\text {technetium revealed increased }}$ uptake of radionuclide in the soft tissues of both thighs, both calves, and right upper arm, while the skeleton revealed no areas of increased uptake. Magnetic resonance imaging revealed widespread replacement of muscle tissue with cystic areas containing mural and nodular calcifications.

\section{REFERENCES}

1. Pachman LM, Veis A, Stock S, Abbott K, Vicari F, Patel P, et al. Composition of calcifications in children with juvenile dermatomyositis: association with chronic cutaneous inflammation. Arthritis Rheum 2006;54:3345-50.

2. Lobo IM, Machado S, Teixeira M, Selores M. Calcinosis cutis: a rare feature of adult dermatomyositis. Dermatol Online J 2008; $14: 10$.

3. Kavala M, Sudogan S, Can B, Zindanci I, Kuru I, Beyhan S, et al. An extremely severe case of cutaneous calcinosis complicating adult dermatomyositis. Clin Exp Dermatol 2009;34:115-6.

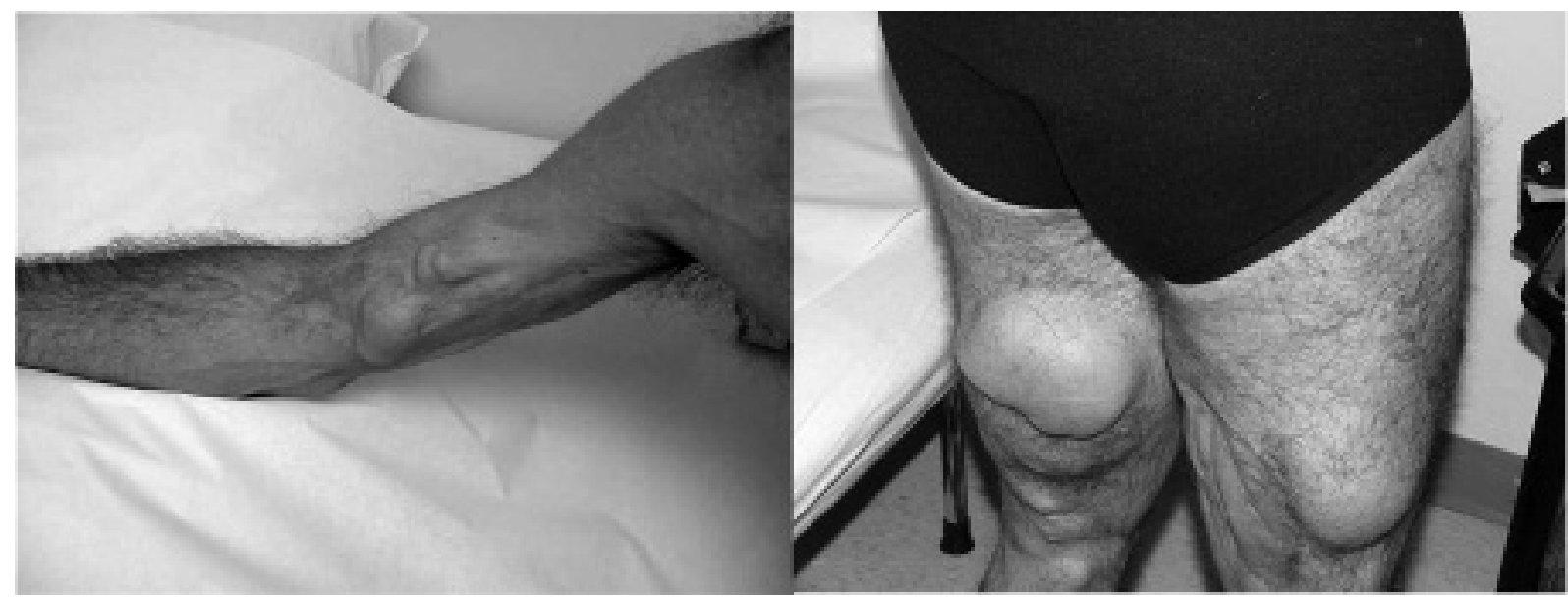

Figure 1. Enlarged calcium deposits caused discomfort and limitation of range of movement. 
Efthimiou P, Kukar M, Kagen LJ. Severe adult-onset calcinosis in a patient with a history of juvenile dermatomyositis. J Rheumatol 2010;37:194; doi:10.3899/jrheum.090628. Departmental affiliation for P. Efthimiou should be as follows: Petros Efthimiou, MD, Chief, Division of Rheumatology, Lincoln Medical and Mental Health Center, Assistant Professor of Clinical Medicine, Weill Cornell Medical College of Cornell University. We regret the error. Doi:10.3899/jrheum.090628C1. 